\title{
Pós-graduação em educação física, inovação e prática pedagógica: reflexões iniciais
}

Alexandro Andrade Professor Titular da UDESC

\section{Resumo}

O presente estudo objetivou analisar introdutoriamente a pós-graduação em Educação Física (PGEF) quanto à produção de conhecimento, desenvolvimento da inovação e seus impactos na prática pedagógica na escola. Abordando o tema descritivamente e criticamente, analisando dados do crescimento quantitativo e qualitativo da PGEF no Brasil, se discute inovação e aplicação de conhecimento na escola. Verifica-se o crescimento significativo tanto em número de programas, mestres e doutores bem como de artigos publicados em periódicos nacionais e internacionais. Embora o crescimento da PGEF esteja ocorrendo, observam-se dificuldades na produção de inovação e de aplicação de conhecimento na escola.

Palavras-chave: Pós-graduação; Educação física escolar; Inovação.

\begin{abstract}
The present study aimed introductorily analyze postgraduate Physical Education in Brazil (PGPE) as the production of knowledge, development of innovation and their impact on teaching practice in school. Addressing the subject descriptive and critically, analyzing PGPE data from quantitative and qualitative growth, discussing innovation and application of knowledge in school. There is significant growth in number of programs, masters and doctorates as well as articles published in national and international journals. Although PGPE growth is occurring, can observed difficulties in production innovation and application of knowledge in school.
\end{abstract}

Keywords: Postgraduate; Physical education; Innovation. 


\section{Reflexões e pressupostos}

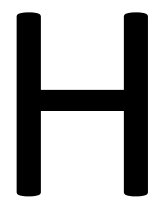

á indiscutivelmente na Educação Física Brasileira um processo de desenvolvimento marcante em sua pós-graduação - PGEF materializado no crescimento dos números relacionados a ela.

Nas últimas três décadas especialmente, verifica-se um aumento do número de mestres e doutores formados, aumento na produção intelectual bem como da participação da Educação Física no sistema nacional de pós-graduação e em editais públicos e privados.

Paralelamente a este processo, nas ciências em geral também se acentuou o debate em torno da inovação. Atingir patamares de produtividade de inovação no Brasil parece ser uma das prioridades, ao menos no discurso oficial. Há órgãos especificamente relacionados à questão da Inovação, como o Ministério de Ciência e Tecnologia - MCT - e outros órgãos associados, bancos como o Banco Brasileiro de Desenvolvimento Econômico e Social - BNDES e agências de fomento como a FINEP, assim como CAPES e CNPq (INEI, 2013) que cada vez mais tem disponibilizado recursos para financiar, para a formação de mestres e doutores capazes de inovar, quanto para projetos e instituições que se qualifiquem para desenvolver inovação.

Entretanto, o que se observa nos estudos que estamos realizando, bem como em primeiros estudos publicados no Brasil (Kenski, 1995; Silva, Lopes, Netto, 2010; Souza, Luzzi, Pereira, 2010; Marinho, 2012; Bracht, 2011) é que, sem desconsiderar este crescimento e desenvolvimento da pósgraduação brasileira e dos discursos sobre inovação, há dificuldades quanto a aplicação dos conhecimentos técnicos e pedagógicos na escola, assim como há dificuldades na produção e identificação de inovação na Educação Física.

Algumas reflexões e questionamentos impulsionam este trabalho introdutório:

1. Há discrepância entre a explosão de conhecimento produzida pela PG em EF nas últimas décadas em detrimento do desenvolvimento da qualidade da prática pedagógica na EF e esportes na escola? 
2. As ideias da "EF progressista ou renovadora (movimento renovador na denominação de Bracht (2011))" em suas diferentes abordagens, de maneira geral, produziram modificações práticas substanciais na EF tanto nas Universidades quanto na escola?

3. A PGEF produziu e produz inovação? Ela identifica, registra e está interessada em refletir e criticar sua inovação?

4. A PGEF produziu mudanças substanciais na prática pedagógica na EF escolar?

5. Para que tem servido a PGEF?

6. A formação de professores na graduação, voltada para a prática pedagógica da EF na escola, foi significativamente influenciada pela PGEF nas instituições de ensino superior que detém cursos de mestrado e doutorado?

É claro que não temos as respostas a todas estas questões, que exigem diversos estudos, tempo e o devido aprofundamento a cada uma delas. Também há que reconhecer que a proposição das mesmas é em si, contribuição e desafio à EF, quando observada fechada no sistema de PG! Estas inquietações implicam mais do que respostas rápidas e prontas, mas a realização de novas pesquisas e análises críticas posteriores.

Há então que perguntar sobre se este desenvolvimento quantitativo e qualitativo na PGEF tem afetado a realidade da escola e a qualidade da disciplina EF? Se há inovação (?), é necessário analisar se esta inovação exerce impacto na realidade escolar. Este é um ensaio teórico introdutório à questão, não objetivando encerrar o debate ou mesmo apresentar o estado da arte sobre o tema. Pretende sim contribuir no mérito de "levantar a poeira sobre o problema" buscando que o mesmo seja mais e melhor percebido, para na continuidade dos estudos e debates, em textos e artigos futuros, aprofundar a análise, contribuindo para seu enfrentamento. 


\section{Crescimento da PGEF e a prática pedagógica da EF Escolar}

É fácil constatar o crescimento da PGEF no Brasil. Milhares de artigos têm sido publicados por nossos pesquisadores - professores, demonstrando que há significativo avanço em qualidade e quantidade desta PG.

O crescimento e o desenvolvimento de nosso sistema de PGEF no Brasil são pujantes. Como os estudos demonstram há crescimento em qualidade e quantidade, de trabalhos publicados, captação de recursos para financiamento de pesquisas e número de mestres e doutores formados.

Importante contribuição dada por Gamboa (2013) ao apresentar dados sobre o crescimento de nossa PGEF, quando diz que os grupos de pesquisa em 1987 eram organizados em torno de áreas de concentração, mudou para uma nova forma, centrados em projetos e linhas de pesquisa, tendo registrado em 20122.332 linhas de pesquisa nos PPG em educação e 251 nos PPGEF. Levanta questões sobre a política do credencialismo nos PPGEF, acrescido do fator conhecido como "produtivismo acadêmico" ou como chamamos a "Mc Donização da PG". A formação de mestres e doutores em EF no país verificou significativo crescimento, pois se em 1987 havia apenas 04 programas de pós-graduação - PPGEF, em 2012 são 30 PPGEF.

Por outro lado, há publicadas críticas na área em relação à EF tradicional, reducionista à saúde ou ao esporte. Nesta perspectiva verificamse linhas de pesquisa nos PPGEF, embora em baixo número, destinada aos estudos na área pedagógica, não sendo difícil questionar se estes esforços, investimentos e mesmo os estudantes, mestres e doutores formados nesta perspectiva humanista e pedagógica tem conseguido materializar os conhecimentos produzidos em inovação concreta e aplicada? Além disso, questiona-se se este conjunto de conhecimentos efetivamente tem impactado a prática pedagógica da EF na escola? Mais ainda, se a educação física renovadora (Bracht, 2011) produziu efeito significativo na qualidade da pedagogia do movimento humano na escola?

Mesmo que este questionamento possa produzir de inicio reações discordantes, acreditamos que "valha a pena" questionar. Nos congressos da 
área e em reuniões que envolvem pesquisadores dos PPGEF, alguns defenderão que há impacto e outros que diferentemente, afirmarão não haver impacto na EF escolar! Ha dicotomização na EF ao se deparar com a questão "teoria e prática", "pesquisa qualitativa e quantitativa", "ciência dura e ciência soft" que não é exclusiva na $\mathrm{EF}$, mas reflete estas dificuldades.

\section{A EF progressista-renovadora mudou a EF escolar?}

Pergunto: a EF progressista ou o movimento renovador da EF (Bracht, 2011), incluindo suas variantes descritas na literatura, mudou qualitativamente a EF escolar? Esta pergunta parece não estar devidamente aprofundada, ao menos quando observamos a produção de conhecimento da EF na relação da PGEF com a escola. Pouco se vê publicado quanto à avaliação crítica que esta questão impõe!

Parece que a EF escolar não melhorou ao observarmos a realidade concreta da expressiva maioria das escolas no país. Embora não se tenha publicado estudo nacional abrangente e conclusivo sobre a qualidade das aulas de EF ou da pedagogia do movimento humano praticada na disciplina, pode-se verificar com grande facilidade que na maioria dos casos esta qualidade tem até piorado, onde o sucateamento das instalações, acompanhada pela desmotivação, desinteresse docente e de pais e gestores pela disciplina é visível. Há clara dificuldade dos docentes de EF se apropriarem das teorias e conhecimentos produzidos pela EF renovadora. De uma situação onde professores desejavam serem técnicos esportivos valorizados pela comunidade escolar, reducionismo fartamente criticado na literatura, mas que, por isso, dedicavam-se a encontrar talentos esportivos para representação da escola, vê-se no lugar pouco envolvimento de docentes, estudantes e gestores nos projetos políticos pedagógicos - PPP das escolas para um planejamento voltado para a mudança e melhoria da qualidade da EF. Obvio que há exceções, onde por esforços localizados de gestores e professores, a EF escolar é realizada com forte embasamento teórico pedagógico e com vivência prática de qualidade, desenvolvendo não apenas o físico dos estudantes de EF, mas seu intelecto e emoções, sua 
capacidade crítica e cidadania, enfim uma educação abrangente. Mas isto parece não ser regra ou resultado de políticas públicas.

Não tenho duvida de que um currículo fechado e disciplinar, sem compromisso social dificulta não apenas a inovação, mas compromete a qualidade da formação. Professores burocratas centrados na reprodução do conhecimento, no controle de horários, na aplicação de provas e testes, rígidos dificulta a boa formação de um estudante criativo e que caminhe com suas próprias pernas (Andrade, 2012).

Futuros educadores que fazem provas e escrevem "papers" pelos quais receberão notas que lhes permitirão tirar o diploma que atesta que eles aprenderam os saberes que os fazem educadores (Alves, 2009), não parece atender a necessidade das escolas.

Estudantes centrados na nota, no estudo por repetição, com foco apenas na inserção no mercado não desenvolverão inovação (Andrade, 2012).

\section{A PGEF serve à escola?}

A PGEF serve pouco à escola. Subáreas como "Fisiologia do exercício e treinamento desportivo" e as derivadas, assim como a "atividade física e saúde" ganharam grande expressão na PG resultando em significativa produção de projetos, artigos e formação de recursos humanos; entretanto, no caso das linhas na PG voltadas para a pedagogia escolar - EF escolar, tal expressão não se verifica. Por um lado, é necessário reconhecer que a PGEF serve à formação profissional, de professores e pesquisadores mais qualificados, serve para aumentar e melhorar a qualidade - quantidade de nossa produção científica serve para qualificar nossa área para ser mais ouvida e participar de forma mais ativa e influente nos debates sobre os caminhos futuros da ciência e, por exemplo, nos debates sobre prioridades, sobre onde e porque investir melhor os recursos públicos na educação, em ciência e tecnologia, em EF e esporte. Segundo Gamboa (2013, pg. 01):

Na Educação Física em 1987 existia apenas 04 programas (USP/SP, UFSM/RS, UFRJ/RJ e UGF/RJ) o aumento passou para $30 \mathrm{em} \mathrm{2012.} \mathrm{A}$ 
produção passou de 15 dissertações e nenhuma tese para 224 dissertações e 46 teses em 2012.

Há também um crescimento exponencial do número de artigos publicados, como também o desenvolvimento do qualis livro. Nossa PGEF tem impactado a formação na graduação em EF, através dos programas de iniciação científica - IC. Estes programas de financiamento de formação de pesquisadores iniciantes não teriam maior alcance dissociado de programas de PGEF. Há forte impacto dos PPGEF e dos programas de IC na formação de graduação em EF. O que se deve questionar é que subáreas são privilegiadas em detrimento da EF escolar? Por quê? A PGEF sustenta-se também na melhor formação e treinamento dos estudantes para ingressar no próprio sistema de PGEF. Digo "formação e treinamento" intencionalmente, pois para muitos estudiosos, que se tem visto é o treinamento cada vez mais precoce de estudantes produtores de artigos - "papers", onde o acadêmico de graduação recebe sua bolsa para "dar conta apenas de uma parte do projeto, experimento ou mesmo apenas da coleta de dados". Neste sentido Gamboa (2013) reflete que esta geração de conhecimento, baseada no binômio 'pesquisa - pós-graduação' que é conduzida pelo produtivismo acadêmico, está longe de ser considerada como trabalho criativo e produtivo.

Não desconsiderando estas contribuições da PGEF, pode-se questionar sobre o que tem produzido para a escola estes programas de iniciação científica - IC? Minha percepção é que a resposta é negativa!

\section{Há inovação na Pós-graduação em EF? \\ Como esta inovação impacta na escola?}

Existem muitos conceitos de inovação, com diversas aplicações dependendo das áreas nas quais ela se aplica. De forma geral podemos conceituar inovação como um processo que abarca atividades técnicas, gestão, concepção, que resultam na criação ou aperfeiçoamento de produtos ou processos (Silva, Lopes, Netto, 2010, p. 996). 
Nosso grupo de pesquisa está envolvido em alguns projetos de pesquisa e extensão, que investiga inovação, inovação pedagógica e inovação na EF e no esporte em geral. Ao estudar as publicações que incluem "inovação" como tema central em EF, constata-se que a PG EF não inova e indica como consequência, não produzir mudanças substanciais na prática pedagógica na EF. Assim, observando esta realidade deve-se perguntar, pra que PG em EF?

Num estudo realizado em 2012 (Andrade, 2012) foi verificado que na literatura científica em periódicos qualis da capes, havia apenas o registro de dois artigos que incluíam no titulo ou no resumo a palavra "inovação" relacionada à EF ou ao esporte. Assim, observando pela ótica do mesmo produtivismo que tanto pressiona os pesquisadores da área a publicar, a conclusão é simples: na EF não se publica nem registra inovação. Provavelmente inovações são realizadas em projetos e pesquisas nos diversos Programas de pós-graduação, é patente o não registro e a carência de produção intelectual sistematizada. Com raras exceções, não se tem registro, por exemplo, de inovação na aula de EF, inovação quanto à forma de avaliação e aos conteúdos da EF. Efetivamente o que se inovou em relação ao esporte escolar além da crítica adensada e a prática generalizada na escola? Será que estas práticas mais recentemente vivenciadas na EF escolar - atividades mais livres, de decisão e participação coletiva, atividades não esportivas, não técnicas e mais democráticas - ajudam a esconder a falta de um conteúdo da EF que respondam as diversas faixas etárias e níveis de escolarização e aos desafios que deveriam ser enfrentados pela EF escolar para a formação de um cidadão crítico e criativo? Seria justo dizer que, na falta de autocrítica e processos inovadores na EF escolar, mantem-se a não resolução da questão "quais conteúdos são fundamentais a serem trabalhados pela disciplina EF na escola, em relação às faixas etárias, séries ou anos escolares, que estejam conectados interdisciplinarmente aos currículos e PPPs das escolas?”. A educação física atual deve pedir aos alunos para mobilizar interesse, atingir resultados desejados e ter uma experiência emocional significativa. A educação exige um novo modelo de 
educação: a de transmitir conhecimentos que também promovam inovação (Tan, Li, 2009).

A preocupante dificuldade de inovação, na EF na universidade e na escola, não deve obrigatoriamente permanecer assim no futuro.

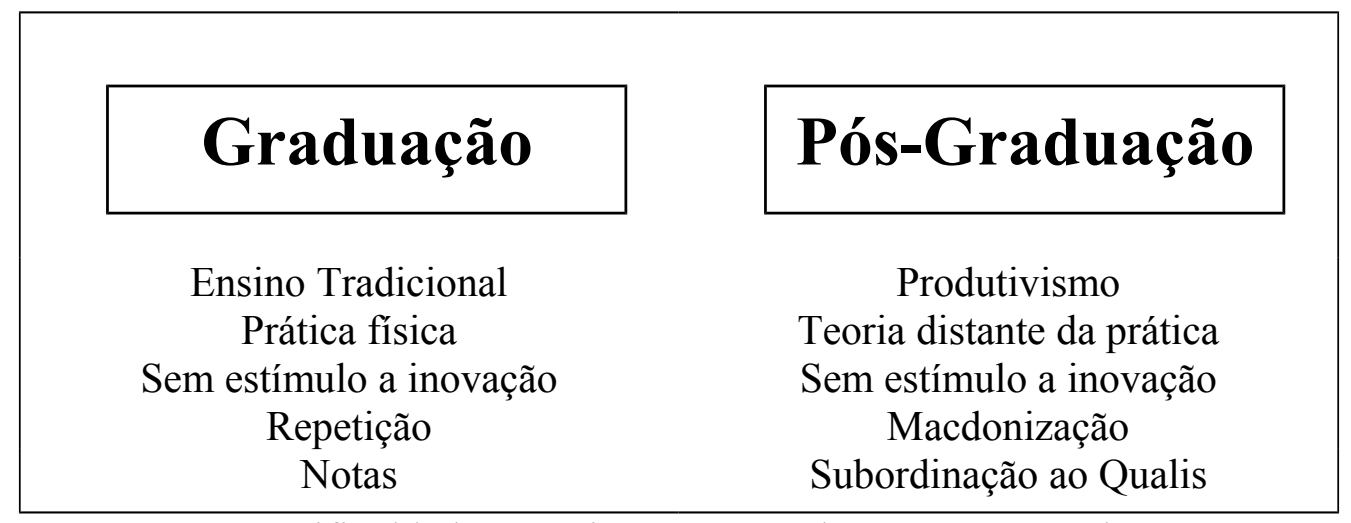

Figura 01. Dificuldades para inovar na graduação e pós-graduação em Educação Física.

Diante deste quadro, perceptível nas escolas, parece que nas instituições de ensino superior - IES, ao menos os intelectuais veem-se mais confortáveis com sua própria capacidade de melhor e mais profundamente interpretar e descrever, sem ter que aplicar ou testar suas teorias, teses e críticas, não conseguindo diminuir o débito social (Demo, 1981, 1985) desta ciência com a prática, com o mundo vivido (Kunz, 1991; Oliveira, 1994), ao menos é o que se verifica nas escolas e na opinião de professores, estudantes e gestores. Ao se observar o aumento da quantidade de artigos publicados, de dissertações e teses defendidas e de programas de PGEF e a precarização da escola e da EF escolar, há certamente uma "correlação negativa"!

Quando há supervalorização do método em detrimento da teoria e da inovação - aplicação, nada muda na realidade escolar; quando não se questiona, orientador, aluno e bancas reproduzem os "materiais e métodos" sem autocritica! Óbvio que com a supervalorização do objeto em detrimento do sujeito, alunos e professores perdem importância para o texto acadêmico e a submissão de todo o esforço intelectual, não para compreender a realidade e buscar melhorá-la ou muda-la, mas para dar conta de um enunciado que atenda as expectativas e exigências dos editores de revistas e 
dos teóricos, muitos deles sem compromisso com a realidade escolar. A questão crucial da educação, portanto, é a formação do educador. Como educar os educadores? (Alves, 2009).

Em pesquisa em desenvolvimento no estado de Santa Catarina - SC em escolas públicas, com gestores, estudantes e professores de EF, tem-se num primeiro momento, a partir de estudo piloto em desenvolvimento, percepções que se repetem, se complementam, mas que demonstram os problemas comuns a estes diferentes segmentos da comunidade escolar. De maneira geral, os gestores indicam que "O governo e as IES abandonaram a escola e a educação pública". Apontam forte descrédito no governo e nas IES e o abandono da escola. Nas entrevistas com professores de Educação Física na Escola, estes indicam descrédito no governo e nas IES, sucateamento da escola em geral e da EF, desvalorização da EF como prática pedagógica ou desportiva. Nas entrevistas com estudantes de Educação Física na Escola, algumas críticas são: Currículos teóricos distantes da prática profissional; Disciplinas excessivamente técnicas e - ou instrumentai; afirmam ser O ESTÁGIO um dos aspectos mais criticados com substituição mecânica do professor supervisor e pouca supervisão e orientação, chegando a afirmar que "Bom estagiário é o que repete aquilo que está posto!”. Os estudantes afirmam ainda que os docentes da IES estão distantes da escola e apresentam pouca experiência pedagógica.

Assim pode-se perguntar sobre qual o papel da PGEF diante deste quadro? A realidade de nossa PGEF esta relacionada ao pouco recurso financeiro disponível no Brasil em relação a outros países aplicados no investimento em pesquisa, onde o compromisso com a mudança e com a educação esta enfraquecido de maneira geral na PGEF diante do produtivismo e da Mcdonização da PGEF.

Novas concepções de ensino, pesquisa e de produção de conhecimento (Taffarel, 1985; Guiraldelli Jr, 1987; Castellani Filho, 1988; Bracht, 1989; Kunz, 1991; Coletivo de autores, 1992; Medina, 1993; Oliveira, 1994; Bracht, 1997) inovaram e alimentaram debates sobre o reconhecimento da Educação Física como área do conhecimento, estatuto científico (Bracht, 1999), dimensão técnica, esportiva, educativa e política e sua inserção no 
desenvolvimento científico nacional e internacional. Por outro lado, no âmbito do esporte de alto rendimento ou da promoção do consumo de produtos esportivos, excluídas as grandes empresas de artigos esportivos que detém seus próprios laboratórios, praticamente nada se verificou de inovação protagonizada por grupos de pesquisa em Educação Física, mesmo entre as que trabalham em favor do rendimento esportivo (Andrade, 2012).

\section{Caminhos possíveis}

Ao nos defrontarmos com esta realidade que aponta para uma separação cada vez maior da PGEF e da realidade da EF escolar, bem como da falta de inovação e inovação pedagógica mais sistemática e ampla, são indicados alguns caminhos possíveis. São eles a) Diminuir a distância entre a PG e a Escola; b) Substituir projetos de pesquisa isolados e transversais por projetos em rede, de longo prazo e em parceria com os sistemas públicos de educação; c) Integrar projetos de pesquisa com extensão e ensino, para inovação e intervenção pedagógica; d) $\mathrm{Na}$ avaliação da $\mathrm{PG}$, valorizar projetos que interfiram na realidade, que promovam mudanças qualitativas e quantitativas da realidade escolar e produzam inovação; c) Nos periódicos, estes devem rever sua tradição de privilegiar para publicação estudos empírico - analíticos e buscar admitir e valorizar artigos com propostas de intervenção e experiências pedagógicas. Neste sentido é justo registrar o esforço do CBCE através da publicação, além da RBCE, dos Cadernos de Formação; d) A produção de conhecimento na PG em EF deve influenciar muito mais as políticas públicas de educação e as decisões de gestão da EF e do esporte na escola; e) Na graduação, é urgente mudar o Foco da reprodução de conhecimentos, métodos e técnicas para valorizar e promover criatividade, inovação e comprometimento social.

A mudança é necessária. A questão é como podemos nós, como educadores de professores de educação física, estruturar nossos programas para facilitar nossos alunos dentro e através do processo de mudança, para que possamos produzir graduados que estejam dispostos a aceitar a mudança como parte de seu ensino e desenvolvimento profissional (Wright et al, 2006). 


\section{Considerações finais}

Muito há que se estudar e debater sobre o tema inicialmente abordado neste ensaio. Não há quem detenha a única razão ou solução para o problema, mas há críticas repetidas e acumuladas em documentos e artigos científicos produzidos. Dois aspectos se destacam sobre a EF, a PG e a escola: está bastante enfraquecido tanto o desenvolvimento de inovação na EF quanto o impacto positivo que a PGEF poderia realizar na EF escolar.

Podemos considerar finalmente que a explosão de conhecimento produzida pela $\mathrm{PG}$ em EF nas últimas décadas não melhorou a qualidade da prática pedagógica na EF escolar, nem mesmo as ideias da "EF progressista ou movimento renovador" em suas diferentes formas, de maneira geral, não produziram modificações práticas substanciais na EF na escola. A PGEF não identifica, registra e parece não estar interessada em refletir e criticar a inovação na área, apresentando claras dificuldades em produzir mudanças substanciais na prática pedagógica na $\mathrm{EF}$.

\section{Referências}

ALVES, R. Desfiz. 75 anos. Campinas, SP: Papirus, 2009, 158.

ANDRADE, A. Inovação em Educação Física: formação profissional deficiente. In: NASCIMENTO, J. V.; FARIAS, G. O. (Org.) Construção da identidade profissional em Educação Física: da formação a intervenção. Florianópolis: Ed. Udesc, 2012.

ANDRADE, A. Presença da inovação na formação de graduação e pós-graduação em educação física e Santa Catarina. Relatório de pesquisa para publicação.

Florianópolis, 2012.

BRACHT, V. Educação Física e Ciência: cenas de um casamento (in)feliz. Ijuí: Unijuí Editora, 1999, 159.

BRACHT, V. Dilemas no cotidiano da Educação Física escolar: entre o desinvestimento e a inovação pedagógica. Salto para o Futuro, v. 21, n. 12, p. 1420, set. 2011.

CASTELLANI FILHO, L. Educaşão Física no Brasil: a bistória que não se conta. Campinas, Papirus, 1988, 225.

DEMO, P. Introdução à Metodologia da Ciência, São Paulo: Atlas, 1985, 118. 
DEMO, P. Metodologia Cientifica em Ciências Sociais, São Paulo: Atlas, 1981, 293.

GAMBOA, S. A. S. A produção do conhecimento em educação: teorias e métodos (1987 - 2012: 25 anos de espetáculo). In: anais IV Seminário de epistemologia e teorias da educação; a produção de conhecimento em Educação: teorias e métodos. IV EPISTED. Unicamp. Campinas: Ed. Unicamp, 2013.

GAMBOA, S. A. S. A dialética na pesquisa em Educação: elementos de contexto. In: FAZENDA, I. Metodologia da pesquisa educacional. $12^{a}$ ed. São Paulo: Cortez, 2011, p. 91-115.

GAMBOA, S. A. S. A pesquisa na Construção da Universidade: $O$ compromisso com a aldeia num mundo globalizado. In: LOMBARDI, J. C. (org.). Pesquisa em Educaşão, História, Filosofia e Temas Transversais. $2^{\mathrm{a}}$ ed. Campinas: Autores Associados, HISTEDBR, 2000, p. 77-93.

GAMBOA, S. A. S. Alternativas metodológicas en el ejercicio de la investigación educativa. Educação e Sociedade. São Paulo, v.19, p. 91-1ll, 1984.

GHIRALDELLI Jr, P. A Evolução das Ideias Pedagógicas no Brasil republicano. São Paulo: Cadernos de Pesquisa, v.60, p.28-37, 1987.

INEI - Instituto nacional de empreendedorismo e inovação: O INEI atua na identificação e difusão das fontes de fomento e financiamento à inovação. Disponível em:

<http://www.inei.org.br/fontes_de_fomento_e_financiamento_a_inovacao>. Acesso em: 01 de março de 2013.

KENSKI, V. M. O impacto da mídia e das novas tecnologias de comunicação na Educação Física. Motriz, v. 1, n. 2, p. 129-133, dez. 1995.

KUNZ, E. Educação Física: ensino e mudanças. Ijuí: Unijuí Editora, 1991, 264.

MARINHO, I. Brasil exporta tecnologia de ponta para atletas. Inovação em Pauta, Brasília. Edição de abr./mai./jun. 2011. Disponível em: http://www. finep.gov.br/imprensa/revista/edicao11/inovacao_em_pauta_11_esporte.pdf >. Acesso em: 05 de outubro de 2012.

MEDINA, J. P. S. A Educação física cuida do corpo... e mente! Campinas: Papirus, 1983, 160.

OLIVEIRA, V. M. Consenso e conflito na educação física brasileira. Campinas: Papirus, 1994, 206.

SILVA C. A. F. da; LOPES, J. P. S. B.; NET'TO, J. A. Educação física, desenvolvimento e inovação: o argumento da hélice tríplice. Motriz: revista de educaşão física. (Online). Rio Claro, v.16, n.4, p. 995-1005, out./dez. 2010.

SILVA, M. S.; BRACHT, V. Na pista de práticas e professores inovadores na educação física escolar. Revista Kinesis, Santa Maria, v.30, n.1, p.80-94, 2012. Disponível em: http://dx.doi.org/10.5902/010283085718. 
SOUZA, E. R; LUZZI, A; PEREIRA, B. O fordismo acadêmico na Educação Física. Revista Brasileira de Ciências do Esporte, Campinas, v. 32, n. 2-4, 2010.

TAFFAREL, C. N. J. Criatividade nas aulas de Educação Física. Rio de Janeiro: Ao Livro Técnico, 1985, 86.

TAN, Z.H.; LI, S. Multimedia Technology in Physical Education. In: 2009 International Symposium on Computer Network and Multimedia Technology (Cnmt 2009), v.1 e 2, p. 1269-1272, 2009.

WRIGHT, S et al. Implications of Student Teachers' Implementation of a Curricular Innovation. Journal of Teaching in Physical Education, v.25, p. 310-328, 2006. 